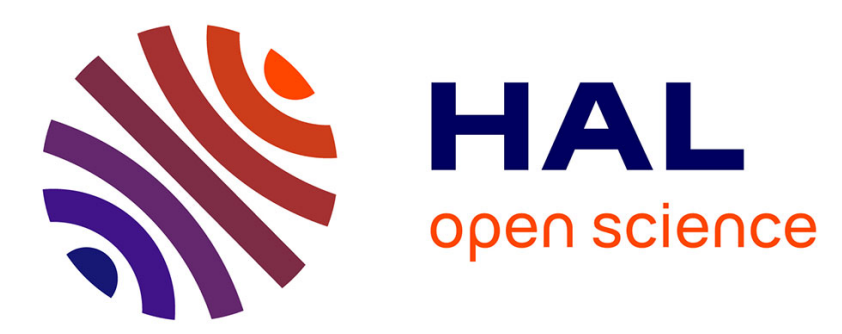

\title{
Nonlinear Time-Dependent Behavior of Composite Steel-Concrete Beams
}

Quang Huy Nguyen, Mohammed Hjiaj

\section{To cite this version:}

Quang Huy Nguyen, Mohammed Hjiaj. Nonlinear Time-Dependent Behavior of Composite Steel-Concrete Beams. Journal of Structural Engineering, 2016, 42 (5), pp.04015175. 10.1061/(ASCE)ST.1943-541X.0001432 . hal-01326285

\section{HAL Id: hal-01326285 \\ https://hal.science/hal-01326285}

Submitted on 15 Nov 2016

HAL is a multi-disciplinary open access archive for the deposit and dissemination of scientific research documents, whether they are published or not. The documents may come from teaching and research institutions in France or abroad, or from public or private research centers.
L'archive ouverte pluridisciplinaire HAL, est destinée au dépôt et à la diffusion de documents scientifiques de niveau recherche, publiés ou non, émanant des établissements d'enseignement et de recherche français ou étrangers, des laboratoires publics ou privés. 


\title{
Nonlinear time-dependent behavior of composite steel-concrete beams
}

\author{
Quang-Huy Nguyen ${ }^{1}$ Not a Member, ASCE and Mohammed Hjiaj ${ }^{2}$ Member, ASCE
}

\begin{abstract}
This paper presents a mixed finite element model for the nonlinear time-dependant analysis of composite beams with partial shear connection. The key idea is to consider, as a first approach, a viscoelastic/plastic model for the concrete slab in order to simulate the interaction between the time effects of concrete, such as creep and shrinkage, and the concrete cracking. Creep is taken into account via linear ageing viscoelasticity, while cracking is modeled using an elasto-plastic model with softening. A nonlinear isotropic/kinematic hardening model is adopted for steel behavior and an appropriate nonlinear constitutive relationship is utilized for the shear stud. A consistent time-integration is performed by adopting the Euler backward scheme. Finally, comparisons between the numerical results and experimental data available in the literature are undertaken to validate the accuracy of the model. It is shown that the interaction between cracking and time effects (creep and shrinkage) significantly increases the deflection.
\end{abstract}

Keywords: Composite beam, time effects, nonlinear creep, cracking, mixed formulation.

\section{INTRODUCTION}

Steel-concrete composite structures are common practice today in bridges and industrial buildings. The advantages of both materials lead to a very economic alternative especially in terms of high bearing capacity. The serviceability of such structures is fundamentally affected by creep and cracking and their interaction, which make the structure behavior

\footnotetext{
${ }^{1}$ Associate Professor, Université Européenne de Bretagne - INSA de Rennes, 20 avenue des Buttes de Coësmes, CS 70839, F-35708 Rennes Cedex 7, France

${ }^{2}$ Professor, Université Européenne de Bretagne - INSA de Rennes, 20 avenue des Buttes de Coësmes, CS 70839, F-35708 Rennes Cedex 7, France
} 
becomes prominent nonlinear. Recent publications have highlighted the effect of creep and shrinkage on the overall behavior of composite beams. The authors have adopted in most cases linear ageing viscoelasticity which can be described using either a hereditary integral formulation or a differential formulation with internal variables. The former formulation is not easy to handle and the most straightforward manner to deal with such constitutive law is to approximate the hereditary integral by a discrete sum according to the trapezoidal or the midpoint rule. Therefore, the storage of the entire stress history is required. This method, called the step-by-step or general method, has been proposed by Bažant and Wu (1972). For practical applications, the so-called algebraic methods, which ignore stress history, have been proposed (McMilan 1916; Hansen 1964; Bažant 1972). Obviously, the algebraic methods give different levels of accuracy depending on the degree of refinement of the quadrature formulas adopted (Dezi and Tarantino 1996). The problem of the storage of stress history can be elegantly overcome by adopting a differential formulation (Bažant and Wu 1973; Bažant and $\mathrm{Wu}$ 1974). By expanding the kernel of the hereditary integral into a Dirichlet serie, the integral-type stress-strain relation can be transformed into a rate-type stress-strain relation based on Kelvin chain or Maxwell chain spring-dashpot model of ageing viscoelasticity. In this strategy, the stress or strain history is memorized via a limited number of internal variables. However, the main drawback of differential formulation is the determination of Dirichlet series coefficients which appears to be quite complicated.

It has been shown that linear viscoelasticity with age-dependent constitutive parameter is not able to correctly predict the long term behavior of concrete under high load levels (Ngab et al. 1981). Indeed, several experimental studies indicate that under high sustained loads, cracks grow and interact with the creep response of the bulk concrete. This interaction may lead to a reduction of the ultimate bearing capacity of structures Bažant and Xi 1994). This is often denoted as nonlinear creep which is a quite complex phenomenon. Several attempts have been made to model the interaction between creep and concrete damage. 
The first models for time-dependent behavior of concrete (creep and relaxation) together with instantaneous non-linear behavior consisted of some kind of superposition in terms of strains between a non-linear explicit stress-strain curve $\sigma=f(\varepsilon)$ (total strain model) and a linear time-dependent model. This approach was adopted by Carol and Murcia (1989) and Fragiacomo et al. (2004) in which the creep of concrete was taken into account using Maxwell's generalized rheological model through a step-by-step time increment procedure. Usually, these types of explicit or total strain approaches are relatively simple and inexpensive compared with other more complex incremental formulations, and allow the engineer to perform the time-dependent static analysis of frames. However, these models seems to be incapable of representing some quite significant experimental features of concrete behavior and more advanced approaches have been devised. One route is to consider the concept of energy activation and rate dependent plasticity (softening) as proposed by Bažant and Jirásek (1993). In a second approach, a standard rheological model for creep is incorporated into the fictitious crack model in order to simulate time dependency of crack opening (Zhou and Hillerborg 1992; Barpi and Valente 2003). In the last class of models, rheological models are built up by combining either smeared crack representation (softening plasticity) or damage model with ageing linear viscoelasticity. The main advantage of the last class of the model is the ease in the implementation as well as the effectiveness in reproducing key feature of the nonlinear cracking process. Barpi and Valente (2003) have enhanced the latter approach using a fractional order rate law. Benboudjema et al. (2005) proposed a sophisticated hydro-mechanical model accounting for the full coupling between drying, shrinkage, creep and cracking. In their model, a new creep constitutive law, based on microscopic considerations of the role of water, is elaborated and coupled with an improved version of the drying creep model proposed by Bažant and Chern (1985) in order to account for the interaction between the solid skeleton and the water.

In composite steel-concrete beams with flexible connectors, a slip at the steel-concrete 
interface occurs, which cannot be neglected in the analysis and the design of composite beams. A state of the art on the time-dependent behavior of steel-concrete structures can be founded in Ranzi et al. (2013). At the very beginning, time-dependent analysis of composite beams was carried out by assuming full interaction between the concrete slab and the steel beam that is no slip occurs at the steel/concrete interface. This leads to analytical procedures for time-dependent analysis of composite steel-concrete cross-sections in full interaction that have been proposed by Gilbert (1989). Early papers on time-analysis of composite beams taking into account partial shear interaction were published by Bradford and Gilbert (1992); Tarantino and Dezi (1992, 1993). Bradford and Gilbert (1992) proposed a method using an equivalent transformed section approach for the time-dependent response of simply supported steel-concrete composite beams. Tarantino and Dezi (1992) adopted the step-by-step approach to discretize the constitutive concrete model which was combined with the finite-difference method for the space discretization. Virtuoso and Vieira (2004) developed a force-based finite element formulation using the rate-type method to model the time-dependent behavior of the concrete. Recently, closed-form solutions have been proposed in Nguyen et al. 2010a, 2010b) for the general method, in Faella et al. (2002); Ranzi and Bradford (2005) for algebraic methods and in Jurkiewiez et al. (2005) for rate-type method. It is worth mentioning that all above-mentioned research papers are based on linear viscoelasticity ignoring the interaction between time effects and instantanuous concrete crack/plasticity. Fragiacomo et al. (2004) have proposed a FE model for collapse and longterm analysis of composite beams. This model takes into account the partial interaction, concrete creep and shrinkage and the nonlinear behavior of component materials. Concrete creep is taken into account using Maxwell's generalized rheological model. The nonlinear behavior of component materials is considered through a new nonlinear iterative procedure called the modified secant stiffness method, particularly effective for this type of problem.

The purpose of the article is to develop a FE model for the long-term analysis of composite 
beams with partial shear connection taking into account the interaction between the time effects and the nonlinear behavior of concrete (cracking). This model is based on the two fields mixed force-displacement formulation with nonlinear constitutive relationships for each components (Zienkiewicz and Taylor 1989; Ayoub and Filippou 2000; Nguyen et al. 2009). The mixed formulation is adopted in our work because it combines the advantages of the displacement and force formulations while overcoming most of their limitations, especially for nonlinear analysis of composite beams in partial interaction (Spacon and El-Tawil 2004). Regarding the nonlinear time-dependent behavior of concrete, a viscoelastic/plastic model is proposed in order to take into account the interaction between creep, shrinkage and plasticity (smeared-crack model). The key idea, which is borrowed from van Zijl et al. (2001), is to combine, as a first approach, a viscoelastic creep model with a continuum plasticity model. Creep is formulated via Kelvin chain spring-dashpot model of aging viscoelasticity (differential formulation) proposed by Jirásek and Bažant (2002). The concrete cracking is modeled using an 1D elasto-plastic model with softening proposed by the first author (Nguyen et al. 2009). A consistent time-integration is performed by adopting the Euler backward scheme. A nonlinear isotropic/kinematic hardening model is adopted for steel behavior (Mahnken 1999) and an appropriate nonlinear constitutive relationship is utilized for the shear stud (Ollgaard et al. 1971; Aribert and Labib 1982). The proposed FE model is employed to investigate the nonlinear long-term behavior of a two-span continuous composite beam tested by Gilbert and Bradford (1995). The accuracy of the model is assessed by comparing the predicted deflections against measured deflections. Finally, the contribution of nonlinear creep is evaluated by comparing the deflections predicted by the proposed model against those provided by ageing linear viscoelasticity.

\section{VISCOELASTIC-PLASTIC MODEL FOR CONCRETE}

In the proposed viscoelastic-plastic model, it is assumed that total strain rate $\dot{\varepsilon}$ is defined 
as the sum of different contributions

$$
\dot{\varepsilon}=\dot{\varepsilon}^{\mathrm{ve}}+\dot{\varepsilon}^{\mathrm{p}}+\dot{\varepsilon}^{\mathrm{sh}}
$$

where $\dot{\varepsilon}^{\mathrm{ve}}$ is viscoelastic strain rate due to concrete creep; $\dot{\varepsilon}^{\mathrm{p}}$ is strain rate due to plasticity/cracking; and $\dot{\varepsilon}^{\text {sh }}$ is shrinkage strain rate. The rheological viscoelastic/plastic model is illustrated in Fig 1. The creep strain rate is evaluated here via an ageing rheological Kelvin chain (with Kelvin elements placed in serial), while the cracking strain is formulated using continuum plasticity theory (smeared cracking model). Further, the shrinkage strain rate can be evaluated by utilizing shrinkage models proposed in design codes (ACI209 1997; Bažant and Baweja 1995; CEB-FIB 1990).

In this work, concrete creep is modeled using the rate-type formulation with internal variables of the linear viscoelasticity, initially proposed by Bažant and $\mathrm{Wu}$ (1974). This formulation is based on expanding the creep function $J(t, \tau)$ into a Dirichlet series:

$$
J(t, \tau) \approx \frac{1}{E_{0}}+\sum_{i=1}^{m} \frac{1}{D_{i}(\tau)}\left[1-\exp \left(-\frac{t-\tau}{\tau_{i}}\right)\right]
$$

where $\tau_{i=1 . . m}$ are fixed parameters called the retardation times; $E_{0}$ is the asymptotic modulus and $D_{i=1 . . m}$ are age-dependent moduli which are determined by numerical identification to analytical creep function of CEB-FIB 1990. The details of this identification can be found in Nguyen (2009). The approximation of the creep function leads to a Kelvin chain of $m$ units with ageing moduli $E_{m}(t)$ and dashpot viscosities $\eta_{m}(t)$ as shown in Fig.1. For this chain, the viscoelastic strain can be expressed as

$$
\varepsilon^{\mathrm{ve}}(t)=\frac{\sigma(t)}{E_{0}}+\sum_{i=1}^{m} \varepsilon_{i}(t)
$$


where $\varepsilon_{i}(t)$ is the strain of each Kelvin unit and must satisfy the following rate-type equation:

$$
E_{i}(t) \dot{\varepsilon}_{i}(t)+\dot{\eta}_{i}(t) \dot{\varepsilon}_{i}(t)+\eta_{i}(t) \ddot{\varepsilon}_{i}(t)=\dot{\sigma}(t)
$$

The above differential equation can be solved using the exponential algorithm developed by Bažant (1971) for ageing concrete creep, which results in the following relationship between the stress increment $\Delta \sigma$ from the time $t_{n}$ to the time $t_{n+1}$ and the corresponding viscoelastic strain increment $\Delta \varepsilon^{\mathrm{ve}}$ :

$$
\Delta \sigma=E^{\mathrm{ve}} \Delta \varepsilon^{\mathrm{ve}}+\widetilde{\sigma}_{n}
$$

where $E^{\mathrm{ve}}$ is an effective stiffness modulus, which depends only on the current time $t_{n+1}$; and $\widetilde{\sigma}_{n}$ is a viscous stress which accounts for the whole stress history. Full details of this exponential algorithm can be found in Jirásek and Bažant (2002).

In the present study, the cracking phenomena is described with a continuum plasticity model in which the plastic strain rate is determined by the plastic flow rule:

$$
\dot{\varepsilon}^{\mathrm{p}}=\dot{\lambda} \frac{\partial \Phi}{\partial \sigma} ; \dot{\lambda} \geq 0 \text { and } \Phi \leq 0
$$

where $\dot{\lambda}$ is the plastic multiplier and $\Phi$ is the yield/craking function. Assuming isotropic hardening/softening, the yield function takes the following form in 1-D:

$$
\Phi= \begin{cases}\sigma-R_{t}(p) & \text { in tension } \\ -\sigma-R_{c}(p) & \text { in compression }\end{cases}
$$

in which $R_{t, c}(p)$ is the hardening/softening functions and $p$ the equivalent plastic strain that describes the hardening/softening behavior. In tension, the following hyperbolic softening 
law is adopted (Nguyen 2009):

$$
R_{t}(p)=\frac{f_{t}}{\left(1+\frac{f_{t} l_{e q}}{G_{t}} p\right)^{2}}
$$

where $f_{t}$ is the tension strength; $G_{t}$ the fracture energy; and $l_{e q}$ the equivalent length of the respective $\mathrm{FE}$ integration point which is introduced according to the concept of constant fracture energy to avoid the loss of objectivity due to the strain localization (Bažant and Oh 1983; Coleman and Spacone 2001).

In compression, the expressions of the hardening/softening functions will be determined such as to reproduce the uniaxial stress-strain explicit function given by Krätzig and Pölling (2004) which fits well with experiments. This function is illustrated by three parts in Fig,2. Elastic part: below the initial yield/damage stress $f_{c y}=f_{c} / 3$ linear-elastic behavior is assumed. Hardening part: the stress grows until failure strength $f_{c}$, consequently the tangential stiffness decreases from initial stiffness to zero (horizontal tangent). Softening part: After exceeding the compression strain $\varepsilon_{c}$, localization of damage occurs in this softening region. The softening branch depends on the fracture energy and on the characteristic length leq to avoid possible ill-posedness problem (Bažant and Oh 1983). The explicit uniaxial stressstrain expression has the form:

$$
\sigma(\varepsilon)= \begin{cases}E_{c} \varepsilon & \text { for } \varepsilon \geq-\varepsilon_{c y} \\ \frac{\frac{E_{c i} \varepsilon}{f_{c}}+\left(\frac{\varepsilon}{\varepsilon_{c}}\right)^{2}}{1-\left(\frac{E_{c i} \varepsilon_{c}}{f_{c}}-2\right) \frac{\varepsilon}{\varepsilon_{c}}} f_{c} & \text { for }-\varepsilon_{c y}>\varepsilon \geq-\varepsilon_{c} \\ \frac{2+\gamma_{c} f_{c} \varepsilon_{c}}{2 f_{c}}+\gamma_{c} \varepsilon+\frac{\gamma_{c}}{2 \varepsilon_{c}} \varepsilon^{2} & \text { for } \varepsilon<-\varepsilon_{c}\end{cases}
$$


where

$$
E_{c i}=\frac{f_{c}^{2}}{2 E_{c} \varepsilon_{c}^{2}}-\frac{f_{c}}{\varepsilon_{c}}+\frac{3 E_{c}}{2} ; \quad \varepsilon_{c y}=\frac{f_{c}}{3 E_{c}} \text { and } \gamma_{c}=\frac{\pi^{2} f_{c} \varepsilon_{c}}{2\left(\frac{G_{c l}}{l_{e q}}-\frac{f_{c}^{2}}{2 E_{c}}\right)^{2}}
$$

with $f_{c}$ being the failure stress and $\varepsilon_{c}$ the corresponding strain. $E_{c}$ is the initial modulus of elasticity and $G_{c l}$ the localized crushing energy.

The identification of the hardening and softening functions is performed as follows. According to the Hooke's law, the stress is expressed as

$$
\varepsilon=\frac{\sigma}{E_{c}}+\varepsilon^{\mathrm{p}}
$$

Otherwise, the associated plastic evolution equations reads

$$
\dot{\varepsilon}^{\mathrm{p}}=-\dot{p}=-\dot{\lambda}
$$

Integrating the above relation, one obtains

$$
\varepsilon^{\mathrm{p}}=-p
$$

From the yield condition, one has

$$
R_{c}=-\sigma
$$

Inserting Eqs. (13) and (14) into (11), one obtains

$$
\varepsilon=-\frac{R_{c}}{E_{c}}-p
$$


By introducing the relations (14) and (15) into (9), one obtains

$$
R_{c}= \begin{cases}\frac{\frac{E_{c i}}{f_{c}}\left(\frac{R_{c}}{E_{c}}+p\right)-\frac{1}{\varepsilon_{c}^{2}}\left(\frac{R_{c}}{E_{c}}+p\right)^{2}}{1+\left(\frac{E_{c i}}{f_{c}}-\frac{2}{\varepsilon_{c}}\right)\left(\frac{R_{c}}{E_{c}}+p\right)} f_{c} & \text { for } p \geq \hat{p} \\ \frac{1}{2+\gamma_{c} f_{c} \varepsilon_{c}}-\gamma_{c}\left(\frac{R_{c}}{E_{c}}+p\right)+\frac{\gamma_{c}}{2 \varepsilon_{c}}\left(\frac{R_{c}}{E_{c}}+p\right)^{2} & \text { for } p<\hat{p}\end{cases}
$$

where

$$
\hat{p}=\varepsilon_{c}-\frac{f_{c}}{E_{c}}
$$

By solving the equation $(16)$ for the hardening/softening function $R_{c}$, one obtains:

$$
R_{c}= \begin{cases}\sqrt{\xi_{1} p^{2}+\xi_{2} p+\xi_{3}^{2}}-\xi_{4} p-\xi_{3} & \text { with } p \geq \hat{p} \\ \frac{1}{3} \sqrt[3]{\sqrt{\left(\sum_{i=0}^{3} \alpha_{i} p^{i}\right)^{2}+\left(\sum_{i=0}^{2} \beta_{i} p^{i}\right)^{3}} \pm \sum_{i=0}^{3} \alpha_{i} p^{i}+\frac{2}{3} E_{c}\left(\varepsilon_{c}-p\right)} & \text { with } p<\hat{p}\end{cases}
$$

in which $\xi_{1 . .4}, \beta_{0,1}, \alpha_{0.2}$ and $\mu_{0 . .3}$ are the parameters which are determined through the material parameters such as $f_{c}, \varepsilon_{c}, E_{c}$ and $G_{c l}$, as given in Appendix.

\section{Integration of the viscoelastic/plastic model}

Numerical implementation of the model requires integrating the rate form of the constitutive relations for a finite time step $\Delta t=t_{n+1}-t_{n}$. The objective is to compute, for a given set of state variables at the time $t_{n}$, a shrinkage strain increment $\Delta \varepsilon^{\text {sh }}$ and a total strain increment $\Delta \varepsilon$, the respective updated state variables at the end of the time step $t_{n+1}$. An Euler-Backward algorithm is utilized for this purpose since it has the property of being stable (Ortiz and Popov 1985; Simo and Hughes 1997). 
The numerical integration of the model is carried out by the following procedure:

1. Compute the effective modulus $E^{\mathrm{ve}}$ and the viscous stress $\widetilde{\sigma}_{n}$ according to the exponential algorithm (Jirásek and Bažant 2002).

2. Predictor: compute viscoelastic trial stress and test for plastic loading

$$
\begin{aligned}
& \sigma_{n+1}^{\text {trial }}=\sigma_{n}+E^{\mathrm{ve}}\left(\Delta \varepsilon-\Delta \varepsilon^{\mathrm{sh}}\right) \\
& \Phi^{\text {trial }}=\Phi\left(\sigma_{n+1}^{\text {trial }}, p_{n}\right)
\end{aligned}
$$

If $\Phi^{\text {trial }} \leq 0$

then viscoelastic step: set $(\bullet)_{n+1}=(\bullet)_{n+1}^{\text {trial }}$ and exit

else viscoelastic/plastic step: proceed to step (3).

3. Corrector: Determine $\Delta \lambda$ by solving

$$
\Phi\left(\sigma_{n+1}^{\text {trial }}-E^{\mathrm{ve}} \operatorname{sign}\left(\sigma_{n+1}^{\text {trial }}\right) \Delta \lambda, p_{n}+\Delta \lambda\right)=0
$$

with Newton-Raphson method and update the others variables

$$
\begin{aligned}
p_{n+1} & =p_{n}+\Delta \lambda \\
\varepsilon_{n+1}^{\mathrm{p}} & =\varepsilon_{n}^{\mathrm{p}}+\operatorname{sign}\left(\sigma_{n+1}^{\text {trial }}\right) \Delta \lambda \\
\sigma_{n+1} & =\sigma_{n+1}^{\text {trial }}-E^{\mathrm{ve}} \operatorname{sign}\left(\sigma_{n+1}^{\text {trial }}\right) \Delta \lambda
\end{aligned}
$$

4. Compute the consistent tangent modulus by

$$
E_{n+1}^{\mathrm{tg}}=E^{\mathrm{ve}}\left(1-\frac{E^{\mathrm{ve}}}{E^{\mathrm{ve}}+\frac{\mathrm{d} R}{\mathrm{~d} p}}\right)
$$




\section{Qualitative validation of the algorithm}

The proposed model is used to simulate a relaxation test. We consider the concrete specimen C30 suggested in the CEB-FIB 1990. The length of the specimen is $200 \mathrm{~mm}$ and its cross-section is $100 \times 100 \mathrm{~mm}^{2}$. This specimen is subjected to an imposed compressive displacement at its end. Creep and shrinkage functions recommended by the CEB-FIB 1990 are utilized considering that the cement is normal hardening and the humidity $(\mathrm{RH})$ is about 80\%.The following material parameters are adopted: $f_{c}=38 \mathrm{MPa} ; f_{t}=2.9 \mathrm{MPa} ; E_{c}=33500$ $\mathrm{MPa} ; \varepsilon_{c}=0.22 \% ; G_{c}=30 \mathrm{kN} / \mathrm{m} ; G_{t}=0.06 \mathrm{kN} / \mathrm{m} ;$ and $l_{e q}=21 \mathrm{~mm}$. The comparison of the time evolution of the stress predicted by the proposed model against simulation with the linear viscoelastic model are presented in Fig. 3. It can be observed that, under creep and shrinkage effects, the stress relaxes from a negative value (compression) until it reaches the tensile strength at 300 days. At this stage, the plastic flow (cracking) begin which results in a decrease of the stress. This drop is necessary as the stress need to remain inside the yield surface. Fig. 4 depicts the time evolution of the strains. As can be seen the total strain is constant over the time because of the imposed displacement (relaxation test). The shrinkage strain is stress-independent and increase in magnitude with time in a monotonic way whereas the creep strain is stress-dependent and varies accordingly. In the present relaxation test, shrinkage will generate tension stresses while creep stresses are compressive. As both the creep and shrinkage strains increase in magnitude but with opposite sign, the yield stress will be reached at a certain time instant. At this stage, plastic deformation will start to develop in order to maintain the stress on the yield surface. However, with the presence of shrinkage strain which is negative, the viscoelastic strain has to vary initially in the contrary way of the shrinkage strain in order to keep the total strain constant. Then the plastic flow is active (at 300 days), the plastic strain starts to increase with time. This leads to a decrease of the viscoelastic strain observed in Fig. 4. The numerical results show that the proposed model seems to be able to represent the cracking phenomena due to shrinkage (Fig. 3).

\section{NONLINEAR ISOTROPIC/KINEMATIC HARDENING ELASTO-PLASTIC MODEL}




\section{FOR STEEL}

In our work, the von Mises plasticity model with combined isotropic and kinematic hardening is adopted for steel. An extensive description for formulation constitutive rate equations of this model can be found in Doghri (1993) and Mahnken (1999), and we only present here a summary of the resulting set of equations for the 1-D problem:

- Yield surface

- Isotropic hardening stress

- Flow rule

- Equivalent plastic strain evolution

- Kinematic hardening evolution

$$
\begin{aligned}
\Phi & =|\sigma-X|-\left(f_{y}+R\right)=0 \\
R & =R(p)=c\left(1-\mathrm{e}^{b p}\right) \\
\dot{\varepsilon}^{\mathrm{p}} & =\dot{\lambda} \operatorname{sign}(\sigma-X) \\
\dot{p} & =\dot{\lambda} \\
\dot{X} & =k_{1} \dot{\varepsilon}^{\mathrm{p}}-k_{2} X \dot{p}
\end{aligned}
$$

where $b, c, k_{1}$ and $k_{2}$ are material parameters. The numerical integration algorithm proposed by Mahnken (1999) is used and implemented in our FE code (Nguyen 2009).

\section{CONSTITUTIVE RELATIONSHIP FOR SHEAR CONNECTORS}

The constitutive relationship proposed by Ollgaard et al. (1971) is considered for the stud shear connector. The analytical relationship between the shear force $Q_{s c}$ and the slip $g$ of a generic stud is given by

$$
Q_{s c}=Q_{\max }\left(1-\mathrm{e}^{-c_{1}|g|}\right)^{c_{2}}
$$

where $Q_{\max }$ is the ultimate strength of the stud shear connector; $c_{1}$ and $c_{2}$ are coefficients to be determined from experimental results (Aribert and Labib 1982).

It is worth to mention that the non-hysteretic behavior is adopted for the sake of simplicity. A hysteretic constitutive law of shear connection such as the one in Zona et al. (2005) can be easily implemented in the proposed FE model. 


\section{COMPOSITE BEAM ELEMENT FORMULATION}

The mixed finite element method is used to formulate the composite beam element (Zienkiewicz and Taylor 1989). The derivation follows the two-field formulation which uses the integral form of equilibrium and compatibility relations to derive the matrix relation between element generalized forces and corresponding displacements. Most of the following formulation is based on the presentation by Ayoub 2001. First of all, we recall in the following the field equations for composite beams with partial shear interaction in a small displacement setting. According to the notations defined in Fig. 5, these equations are summarized as

- Equations of equilibrium

$$
\partial \mathbf{D}^{i}-\partial_{s c} D_{s c}^{i}-\mathbf{P}_{z}=0
$$

- Equations of compatibility

$$
\begin{aligned}
\partial \mathbf{d}^{i}-\mathbf{e}^{i} & =0 \\
\partial_{s c}^{\mathrm{T}} \mathbf{d}^{i}-g^{i} & =0
\end{aligned}
$$

- Equations of constitutive law

$$
\begin{aligned}
\mathbf{e}^{i} & =\mathbf{e}^{i-1}+f^{i-1} \Delta \mathbf{D}^{i} \\
D_{s c}^{i} & =D_{s c}^{i-1}+k_{s c}^{i-1} \Delta g^{i}
\end{aligned}
$$

where $\mathbf{D}=\left[\begin{array}{llll}N_{c} & N_{s} & M_{c}+M_{s}\end{array}\right]^{\mathrm{T}}$ is section generalized force vector; $D_{s c}$ the bond force per unit length; $\mathbf{P}_{z}=\left[\begin{array}{lll}0 & 0 & p_{z}\end{array}\right]^{\mathrm{T}}$ with $p_{z}$ the external uniformly distributed load; $\mathbf{d}=\left[\begin{array}{lll}u_{c} & u_{s} & v\end{array}\right]^{\mathrm{T}}$

the displacement vector; $\mathbf{e}=\left[\begin{array}{lll}\varepsilon_{c} & \varepsilon_{s} & \kappa\end{array}\right]^{\mathrm{T}}$ section generalized deformation vector; $g$ the relative slip between the concrete slab and the steel beam; superscript $i$ indicates the current 
iteration of the Newton-Raphson (N-R) iteration loop; $f$ the flexibility matrix of the crosssection derived from uniaxial constitutive models for both steel and concrete. $\Delta$ denotes the increments of the corresponding quantities; the operator $\partial$ and $\partial_{s c}$ are given by

$$
\partial=\left[\begin{array}{ccc}
\frac{\mathrm{d}}{\mathrm{d} x} & 0 & 0 \\
0 & \frac{\mathrm{d}}{\mathrm{d} x} & 0 \\
0 & 0 & -\frac{\mathrm{d}^{2}}{\mathrm{~d} x^{2}}
\end{array}\right] \quad ; \quad \partial_{s c}=\left[\begin{array}{c}
1 \\
-1 \\
H \frac{\mathrm{d}}{\mathrm{d} x}
\end{array}\right]
$$

In the two-field mixed formulation, independent shape functions are used for approximating the displacement and force fields along the element. The two fields are written

$$
\begin{aligned}
\mathbf{d}(x) & =\mathbf{a}(x) \mathbf{q} \\
\mathbf{D}(x) & =\mathbf{b}(x) \mathbf{Q}+\mathbf{D}_{0}(x)
\end{aligned}
$$

where $\mathbf{a}(x)$ and $\mathbf{b}(x)$ are the displacement and force interpolation matrices, respectively; $\mathbf{D}_{0}(x)$ is a particular solution accounting for the effects of internal loading on the internal cross-section forces. The mixed beam formulation considered in this study is based on the Hellinger-Reissner variational principle and it is expressed by combining the weak forms of the compatibility equation (33) and equilibrium equation (32). These weak forms may be expressed as

$$
\int_{L} \delta \mathbf{D}^{\mathrm{T}}\left(\partial \mathbf{d}^{i}-\mathbf{e}^{i}\right) \mathrm{d} x+\int_{L} \delta \mathbf{d}^{\mathrm{T}}\left(\partial \mathbf{D}^{i}-\partial_{s c} D_{s c}^{i}-\mathbf{P}_{z}\right) \mathrm{d} x=0 \quad \forall \delta \mathbf{D}, \delta \mathbf{d}
$$

where $\delta \mathbf{D}$ and $\delta \mathbf{d}$ are weighting functions fulfilling the equilibrium and compatibility conditions, respectively. Applying integration by parts for above equation and inserting (35), (36), (38) and (39) into the outcome, one obtains

$$
\delta \mathbf{Q}^{\mathrm{T}}\left(\mathbf{G} \Delta \mathbf{q}^{i}-\mathbf{F}^{i-1} \Delta \mathbf{Q}^{i}+\mathbf{q}_{\mathrm{r}}^{i-1}\right)+\delta \mathbf{q}^{\mathrm{T}}\left(\mathbf{K}_{s c}^{i-1} \Delta \mathbf{q}^{i}+\mathbf{G}^{\mathrm{T}} \Delta \mathbf{Q}^{i}+\mathbf{Q}_{\mathrm{r}}^{i-1}-\mathbf{P}_{\text {ext }}\right)=0
$$


where

$$
\begin{aligned}
\mathbf{G} & =\int_{L} \mathbf{b}^{\mathrm{T}}(\partial \mathbf{a}) \mathrm{d} x \\
\mathbf{F}^{i-1} & =\int_{L} \mathbf{b}^{\mathrm{T}} \mathbf{f}^{i-1} \mathbf{b} \mathrm{d} x \\
\mathbf{q}_{r}^{i-1} & =\mathbf{G q}^{i-1}-\int_{L} \mathbf{b}^{\mathrm{T}} \mathbf{e}^{i-1} \mathrm{~d} x \\
\mathbf{K}_{s c}^{i-1} & =\int_{L}\left(\partial_{s c}^{\mathrm{T}} \mathbf{a}\right)^{\mathrm{T}} k_{s c}^{i-1}\left(\partial_{s c}^{\mathrm{T}} \mathbf{a}\right) \mathrm{d} x \\
\mathbf{Q}_{\mathrm{r}}^{i-1} & =\mathbf{G}^{\mathrm{T}} \mathbf{Q}^{i-1}+\int_{L}\left(\partial_{s c}^{\mathrm{T}} \mathbf{a}\right)^{\mathrm{T}} D_{s c}^{i-1} \mathrm{~d} x \\
\mathbf{P}_{\text {ext }} & =\mathbf{Q}_{\text {ext }}+\int_{L} \mathbf{a}^{\mathrm{T}} \mathbf{P}_{z} \mathrm{~d} x-\int_{L}(\partial \mathbf{a})^{\mathrm{T}} \mathbf{D}_{0} \mathrm{~d} x
\end{aligned}
$$

in which $\mathbf{Q}_{\text {ext }}$ is the vector of nodal applied loads. Since Eq. 41 must be hold for any $\delta \mathbf{Q}^{\mathrm{T}}$ and $\delta \mathbf{q}^{\mathrm{T}}$, it follows that

$$
\left[\begin{array}{cc}
-\mathbf{F}^{i-1} & \mathbf{G} \\
\mathbf{G}^{\mathrm{T}} & \mathbf{K}_{s c}^{i-1}
\end{array}\right]\left[\begin{array}{c}
\Delta \mathbf{Q}^{i} \\
\Delta \mathbf{q}^{i}
\end{array}\right]=\left[\begin{array}{c}
-\mathbf{q}_{\mathrm{r}}^{i-1} \\
\mathbf{P}_{\text {ext }}-\mathbf{Q}_{\mathrm{r}}^{i-1}
\end{array}\right]
$$

Eq. (48) represents in matrix form the two-field mixed formulation for the composite beam with partial interaction. If the first equation in 48 is solved for $\Delta \mathbf{Q}^{i}$ and the result is substituted into the second equation, the following expression results

$$
\mathbf{K}^{i-1} \Delta \mathbf{q}^{i}=\mathbf{P}_{\text {ext }}-\mathbf{Q}_{\text {int }}^{i-1}
$$

where

$$
\begin{aligned}
& \mathbf{K}^{i-1}=\mathbf{G}^{\mathrm{T}}\left[\mathbf{F}^{i-1}\right]^{-1} \mathbf{G} \\
& \mathbf{Q}_{\mathrm{int}}^{i-1}=\mathbf{Q}_{\mathrm{r}}^{i-1}+\mathbf{G}^{\mathrm{T}}\left[\mathbf{F}^{i-1}\right]^{-1} \mathbf{q}_{\mathrm{r}}^{i-1}
\end{aligned}
$$

It should be noted that $\mathbf{K}^{i-1}$ designates the element consistent tangent stiffness at the 
previous Newton-Raphson iteration and $\mathbf{Q}_{\text {int }}^{i-1}$ represents the corresponding element resisting force vector. Further, the formulation has been developed by considering the composite beam element depicted in Fig, 6 where the rigid body modes are not included. Since small displacement hypothesis is adopted in this study, rigid body modes can be incorporated with a simple geometric transformation. The element has 7 displacement degrees of freedom and 6 force degrees of freedom as shown in Fig, 6 .

\section{State determination algorithm}

The implementation of the model in a general purpose finite element analysis program requires the determination of the resisting forces and stiffness matrix that correspond to the displacements of the structural nodes. In a nonlinear structural analysis program each load step corresponds to the application of an external load increment to the structure. The corresponding structural displacement increments are determined and the end displacements are extracted for each element. The process of finding the resisting forces that correspond to the given displacements is known as state determination. The state determination process is made up of two nested stages: (a) the element state determination, in which the element resisting forces for given element displacements are determined; and (b) the structure state determination, in which the element resisting forces are assembled to yield the structure resisting forces. These are then compared with the total applied loads and the difference, if any, yields the unbalanced force vector. In the Newton-Raphson algorithm, the unbalanced forces are then applied to the structure until external loads and internal resisting forces agree within a specified tolerance (Spacone et al. 1996). Note that in the mixed formulation, there are several algorithms depending how the governing equations are linearized. A detailed study of state determination algorithms for nonlinear mixed beam finite elements can be found in Nukala and White (2004). In this study, a direct element state determination following the proposal of Neuenhofer and Filippou (1997) is used. In this algorithm, the residuals at the section and element levels are pushed to structure level and then they are eliminated during global N-R iterations. One the increment displacement at the element 
level $\Delta \mathbf{q}^{i}$ are obtained from the $i^{\text {th }} \mathrm{N}-\mathrm{R}$ iteration at the structure level, the element resisting forces are determined by the flowing steps:

- Calculate element force increments and update

$$
\begin{aligned}
\Delta \mathbf{Q}^{i} & =\left[\mathbf{F}^{i-1}\right]^{-1}\left(\mathbf{G} \Delta \mathbf{q}^{i}+\mathbf{q}_{\mathrm{r}}^{i-1}\right) \\
\mathbf{Q}^{i} & =\mathbf{Q}^{i-1}+\Delta \mathbf{Q}^{i}
\end{aligned}
$$

- Determine the section force increments (at integration points) and update the section generalized deformations

$$
\begin{aligned}
\Delta \mathbf{D}^{i} & =\mathbf{b} \Delta \mathbf{Q}^{i} \\
\mathbf{e}^{i} & =\mathbf{e}^{i-1}+\mathbf{f}^{i-1} \Delta \mathbf{D}^{i}
\end{aligned}
$$

- Update the slip and determine the interface resisting shear force as well as the consistent tangent shear stiffness through shear connector constitutive law (cf. Section 4)

$$
\begin{aligned}
& d_{s c}^{i}=d_{d c}^{i-1}+\left(\partial_{s c}^{\mathrm{T}} \mathbf{a}\right) \Delta \mathbf{q}^{i} \\
& D_{s c}^{i}=D_{s c}\left(d_{s c}^{i}\right) \\
& k_{s c}^{i}=\left.\frac{\mathrm{d} D_{s c}}{\mathrm{~d} d_{s c}}\right|_{d_{s c}^{i}}
\end{aligned}
$$

- Determine the section stiffness from the section constitutive law through fiber integration and deduce the section flexibility matrix $\mathbf{f}^{i}$ (cf. see Nguyen et al. (2009)).

- Calculate $\mathbf{F}^{i}, \mathbf{q}_{r}^{i}, \mathbf{K}_{s c}^{i}$ and $\mathbf{Q}_{\mathrm{r}}^{i}$ by Eqs. (43)-(46) and then the new element stiffness matrix $\mathbf{K}^{i}$ and element resisting force vector $\mathbf{Q}_{\text {int }}^{i}$ are calculated as in (50) and (51) respectively. 


\section{NUMERICAL EXAMPLE}

The purpose of this application is to assess the capability of the proposed model to predict satisfactorily the long-term structural behavior of composite beams with partial interaction. We investigate the long-term deflection of two identical continuous beams (B1 and B2) with two equal spans. The beam B1 was subjected only to its self-weight, i.e. $p_{0}=1.92$ $\mathrm{N} / \mathrm{mm}$, while the beam B2 carried an additional superposed sustained load of $4.75 \mathrm{~N} / \mathrm{mm}$, i.e. $p_{0}=6.67 \mathrm{~N} / \mathrm{mm}$. These continuous beams were tested by Gilbert and Bradford (1995) over a period of 340 days. The dimensions of the tested beams, the loading and the geometric characteristics of the cross-section are shown in Fig. 7. The connector spacing is not given in Gilbert and Bradford (1995) and we assume that the headed studs were uniformly spaced along the beam and the distance between two studs is taken equal to $55 \mathrm{~mm}$. It is worth mentioning that in our model, the connection at the interface slab/joist is modeled by a continuous bond model despite the discrete nature of shear studs. The equivalent continuous connection stiffness is computed by dividing the stiffness of a single shear stud by their spacing along the beam. The concrete compressive strength obtained from the experiments is equal to $27 \mathrm{MPa}$. Accordingly, we can consider for the computer analysis that the concrete is of grade C30. Shrinkage is assumed to start at 7 days. The well-known B3 model (Bažant and Baweja 1995) is selected to predict the creep function and shrinkage strain of concrete. Table 1 presents the constitutive model parameters which are used for the computer analysis. Note that, in this table, all symbols are defined as in the corresponding cited reference.

The mid-span deflections obtained by the proposed model are compared against the experimental results and the numerical results obtained by viscoelastic model with cracked analysis (Nguyen et al. 2010b) in Fig.8 for both beams. It can be seen that the numerical results are in reasonable agreement with the experimental data. Further, the deflection predicted by the proposed model is smaller than the one of cracked analysis. It can be explained on one hand by the fact that the proposed model takes into account the stiffness of 
the concrete in hogging zone while in cracked analysis the concrete contribution along $15 \%$ of the span length on each side of the internal support is neglected (Nguyen et al. 2010b). On the other hand, it is well known that the deflection of composite beams is strongly influenced by the shear connection stiffness which is not the same in their two computer analysis. For example, the shear connection secant stiffness given by the exponential equation (31) is $1317 \mathrm{MPa}$ for $1 \mathrm{~mm}$ of slip. This value is indeed much larger than the one taken in cracked analysis, ie $400 \mathrm{MPa}$ (see Nguyen et al. 2010b).

In order to investigate the time effect of concrete in the plastic range, we consider that the beam is instantly subjected at 7 days to a distributed load $p_{0}$. The loading is supposed to be constant during an analysis of 70 years. Figs $9 \mathrm{a}$ and $9 \mathrm{~b}$ show the evolutions of the mid-span deflection in function of loading for $t=7$ days and in function of time for $p_{0}=20$, 30 and $40 \mathrm{kN} / \mathrm{m}$, respectively. Again, we observe that the deflection increases more or less significant over time. Further, the results indicated that the time effect is more important when the beam is in the nonlinear range (plasticized and cracked). For instant, with $p_{0}=$ $20 \mathrm{kN} / \mathrm{m}$ the beam is still in linear range (see Fig. 9a) and the creep and shrinkage make increase the deflection about $8 \mathrm{~mm}$ while when the beam is plasticized and cracked (with $p_{0}$ $=40 \mathrm{kN} / \mathrm{m}$ ) the time deflection is about $26 \mathrm{~mm}$. Fig 10 presents the time evolution of the bending moment at intermediate support. As can be seen, the bending moment distribution is less important when the beam is more loaded. It can be explained by the fact that under $p_{0}=20 \mathrm{kN} / \mathrm{m}$ the beam is not almost plasticized as under $p_{0}=40 \mathrm{kN} / \mathrm{m}$. Therefore the shrinkage makes it totally plasticized/cracked. As a result, there is an important bending moment redistribution compared to the case of $40 \mathrm{kN} / \mathrm{m}$ as we can see in Fig 10 .

The time evolution of the most tensile fiber stress is shown in Fig,11. As can be seen, the instantaneous stress under service load $p_{0}=6.67 \mathrm{kN} / \mathrm{m}$ (real load level of the test Gilbert and Bradford 1995)) is remain smaller than the tensile stress resistance $f_{t}$. The time effect makes 
the tensile stress go up to $f_{t}$ at $t=10$ days. This fiber is then "plasticized/cracked" therefore the softening curve of stress over time is obtained (see black line in Fig.11). However, for the three other load levels one can observe that the tensile stress decreases over time. That means that the slab cross-section at intermediate support is instantly cracked. The most compressed fiber stress at mid-span versus time curves are plotted in Fig,12. Because of statically indeterminate beam, one can observe the stress relaxations for all load levels. Further, it can be noted that the slab cross-section at mid-span partially compressed at $t=7$ days can become totally tensed under time effect. It can be seen from Fig 12 for the case $p_{0}$ $=6.67 \mathrm{kN} / \mathrm{m}$.

\section{CONCLUSIONS}

In this article, a FE model for the nonlinear time-dependant behavior of composite beams with partial shear connection has been proposed. Two fields mixed force-displacement formulation has been used. A viscoelastic/plastic has been developed for the time-dependent behavior of concrete. This model takes into account the interaction between creep, shrinkage and cracking of concrete. Creep and shrinkage are formulated via Kelvin chain springdashpot model of aging viscoelasticity. The concrete cracking is modeled using an 1D elasto-plastic model with softening proposed by the authors. The proposed FE model has been applied to two-span continuous composite beam to investigate the long term behavior.

Fairly good agreement between the predicted deflections and the measured deflections has been found. The predicted deflections were also compared against the ones obtained by the cracked analysis in (Nguyen et al. 2010b). Good agreement has been observed. The numerical results have been indicated that the deflection can be significantly larger when the nonlinear behavior of concrete is combined with creep and shrinkage. Further, the time effect can produce an important bending moment redistribution in the statically indeterminate beam under serviceability loads. This redistribution becomes less significant if the beam is plasticized/cracked before the acting of time effect. However, further experimental research needs to be conducted to confirm this. 
APPENDIX

$$
\begin{aligned}
\xi_{1} & =\frac{E_{c}^{2} E_{c i}^{2} \varepsilon_{c}^{2}-4 E_{c}^{2} E_{c i} \varepsilon_{c} f_{c}+4 E_{c}^{2} f_{c}^{2}}{4\left(E_{c i} \varepsilon_{c}-2 f_{c}+f_{c}^{2} /\left(E_{c} \varepsilon_{c}\right)\right)^{2}} \\
\xi_{2} & =\frac{E_{c} E_{c i} \varepsilon_{c} f_{c}\left(E_{c} \varepsilon_{c}+E_{c i} \varepsilon_{c}-2 f_{c}\right)-2 E_{c} f_{c}^{2}\left(E_{c} \varepsilon_{c}+f_{c}\right)}{2\left(E_{c i} \varepsilon_{c}-2 f_{c}+f_{c}^{2} /\left(E_{c} \varepsilon_{c}\right)\right)^{2}} \\
\xi_{3} & =\frac{E_{c} \varepsilon_{c}^{2} f_{c}\left(E_{c}-E_{c i}\right)}{2\left(E_{c} E_{c i} \varepsilon_{c}^{2}-2 E_{c} \varepsilon_{c} f_{c}+f_{c}^{2}\right)} \\
\xi_{4} & =\frac{E_{c}\left(E_{c} E_{c i} \varepsilon_{c}^{2}-2 E_{c} \varepsilon_{c} f_{c}+2 f_{c}^{2}\right)}{2\left(E_{c} E_{c i} \varepsilon_{c}^{2}-2 E_{c} \varepsilon_{c} f_{c}+f_{c}^{2}\right)} \\
\alpha_{0} & =\frac{27 E_{c}^{2} \varepsilon_{c}}{\gamma_{c}}-\frac{18 E_{c}^{3} \varepsilon_{c}^{2}}{f_{c} \gamma_{c}}-E_{c}^{3} \varepsilon_{c}^{3} \\
\alpha_{1} & =\frac{18 E_{c}^{3} \varepsilon_{c}}{f_{c} \gamma_{c}}+3 E_{c}^{3} \varepsilon_{c}^{2} \\
\alpha_{2} & =-3 E_{c}^{3} \varepsilon_{c} \\
\alpha_{3} & =E_{c}^{3} \\
\beta_{0} & =\frac{6 E_{c}^{2} \varepsilon_{c}}{f_{c} \gamma_{c}}-E_{c}^{2} \varepsilon_{c}^{2} \\
\beta_{1} & =2 E_{c}^{2} \varepsilon_{c} \\
\beta_{2} & =-E_{c}^{2}
\end{aligned}
$$




\section{REFERENCES}

ACI209 (1997). "Prediction of creep, shrinkage, and temperature effects in concrete structures.

Aribert, J. and Labib, A. (1982). "Modèle calcul élasto-plastique de poutres mixtes à connexion partiell." Construction Metallique, 4.

Ayoub, A. (2001). "A two-field mixed variational principle for partially connected composite beams." Finite Elements in Analysis and Design, 37(11), 929-959.

Ayoub, A. and Filippou, F. (2000). "Mixed formulation of nonlinear steel-concrete composite beam element." Journal of Structural Engineering-ASCE, 126(3), 371-81.

Barpi, F. and Valente, S. (2003). "Creep and fracture in concrete: A fractional order rate approach." Engineering Fracture Mechanics, 70(5), 611-623.

Bažant, Z. (1971). "Proccedings of the 1st international conference on structure mechanics in reactor technology, west berlin." Materials and Structures, 4(part H), 119-126.

Bažant, Z. (1972). "Prediction of concrete creep effects using age-adjusted effective modulus mothed." Journal of the American Concrete Institue, 69.

Bažant, Z. and Baweja, S. (1995). "Creep and shrinkage prediction model for analysis and design of concrete structures - model b3." Materials and Structures, 28(6), 357-365.

Bažant, Z. and Chern, J. (1985). "Concrete creep at variable humidity: constitutive law and mechanism." Mater Struct, 18(103), 1-20.

Bažant, Z. and Jirásek, M. (1993). "R-curve modeling of rate and size effects in quasibrittle fracture." Internatinal Journal of Fracutre, 62(4), 355-373.

Bažant, Z. and Oh, B. (1983). "Crack band theory for fracture of concrete." Materials and Structures, 16(3), 155-177.

Bažant, Z. and Wu, S. (1972). "Numerical determination of long-range stress history from strain history in concrete." Materials and Structures, 5(27), 135-141.

Bažant, Z. and Wu, S. (1973). "Dirichlet series creep function for aging of concrete." Journal of the Engineering Mechanics Division (ASCE), 9(2), 367-387. 
Bažant, Z. and Wu, S. (1974). "Rate-type law of aging concrete based on maxwell chain." Materials and Structures, 7(1), 45-60.

Bažant, Z. and Xi, Y. (1994). "Drying creep of concrete: constitutive model and new experiemnts separating its mechanisms." Materials and Structures, 27(1), 3-14.

Benboudjema, F., Meftah, F., and Torrenti, J. (2005). "Interaction between drying, shrinkage, creep and cracking phenomena in concrete." Engineering Structures, 27(2), 239-250.

Bradford, M. and Gilbert, R. (1992). "Composite beams with partial interaction under sustained loads." Journal of Structural Engineering (ASCE), 118(7), 1871-1883.

Carol, I. and Murcia, J. (1989). "A model for the non-linear time-dependent behaviour of concrete in compression based on a maxwell chain with exponential algorithm." Materials ans Structures, 22(3), 176-184.

CEB-FIB (1990). "Model code 1990: Design code. comité euro-international du bétonfédération international de la précontrainte." London: Thomas Telford.

Coleman, J. and Spacone, E. (2001). "Localization issues in force-based frame elements." Journal of Structural Engineering, 127(11), 1257-1265.

Dezi, L. and Tarantino, A. (1993). "Creep in composite continuous beams. i. theoretical treatment." Journal of Structural Engineering ASCE, 119(7), 2095-2111.

Dezi, L. and Tarantino, A. (1996). "Algebraic methods for creep analysis of continuous composite beams." Journal of Structural Engineering ASCE, 122(4), 423-430.

Doghri, I. (1993). "Fully implicit integration and consistent tangent modulus in elastoplasticity." International journal for numerical methods in engineering, 36(22), 3915-3932.

Faella, C., Martinelli, E., and Nigro, E. (2002). "Steel and concrete composite beams: "exact" expression of the stiffness matrix and applications." Computers and Structures, 80, 1001-9.

Fragiacomo, M., Amadio, C., and Macorini, L. (2004). "Finite-element model for collapse and long-term analysis of steelconcrete composite beams." Journal of Structural Engineering ASCE, 80, 489-497.

Gilbert, R. (1989). "Time-dependent analysis of composite steel-concrete sections." Journal 
of Structural Engineering ASCE, 115(2), 341-362.

Gilbert, R. and Bradford, M. (1995). "Time-dependent behavior of continuous composite beams." Journal of Structural Engineering ASCE, 121(2), 319-327.

Hansen, T. (1964). "Estimating stress relaxation from creep data." Materials Research and Standards (ASTM), 4.

Jirásek, M. and Bažant, Z. (2002). Inelastic Analysis of Structures. John Wiley \& Sons.

Jurkiewiez, B., Buzon, S., and Sieffert, J. (2005). "Incremental viscoelastic analysis of composite beams with partial interaction." Computers and Structures, 83(21-22), 1780-91.

Krätzig, W. and Pölling, R. (2004). "An elasto-plastic damage model for reinforced concrete with minimum number of material parameters." Computers and Structures, 82(15-16), $1201-1215$.

Mahnken, R. (1999). "Improved implementation of an algorithm for non-linear isotropic/kinematic hardening in elastoplasticity." Communication in numerical methods in engineering, 15(10), 745-754.

McMilan, F. (1916). "Method of designing rienforced concrete slabs, discussion by ac janni." Transactions ASCE, 80.

Neuenhofer, A. and Filippou, F. (1997). "Evaluation of nonlinear frame finite element models." Journal of Structural Engineering ASCE, 123(7), 958-966.

Ngab, A., Nilson, A., and Slate, F. (1981). "Shrinkage and creep of high strength concrete." ACI Journal, 78(4), 255-261.

Nguyen, Q.-H. (2009). "Modelling of the nonlinear behaviour of composite beams taking into account time effects." Dissertation, INSA de Rennes, France, INSA de Rennes, France.

Nguyen, Q.-H., Hjiaj, M., and Aribert, J.-M. (2010a). "A space-exact beam element for time-dependent analysis of composite members with discrete shear connection." Journal of Constructional Steel Research, 66(11), 1330 - 1338.

Nguyen, Q.-H., Hjiaj, M., and Uy, B. (2010b). "Time-dependent analysis of composite beams with partial interaction based on a time-discrete exact stiffness matrix." Engineering Struc- 
tures, 32(9), 2902-11.

Nguyen, Q.-H., Hjiaj, M., Uy, B., and Guezouli, S. (2009). "Analysis of composite beams in the hogging moment regions using a mixed finite element formulation." Journal of Constructional Steel Research, 65(3), 737-48.

Nukala, P. and White, D. (2004). "Variationally consistent state determination algorithms for nonlinear mixed beam finite elements." Computer Methods in Applied Mechanics and Engineering, 193(33-35), 1647-3666.

Ollgaard, J., Slutter, R., and Fisher, J. (1971). "Shear strength of stud connectors in lightweight and normal weight concrete." Engineering Journal, 8(2), 55-64.

Ortiz, M. and Popov, E. (1985). "Accuracy and stability of integration algorithms for elastoplastic constitutive relations." International journal for numerical methods in engineering, 21(9), 1561-1576.

Ranzi, G. and Bradford, M. (2005). "Analytical solutions for the time-dependent behaviour of composite beams with partial interaction." International Journal of Solids and Structures, 43(13), 3770-3793.

Ranzi, G., Leoni, G., and Zandonini, R. (2013). "State of the art on the time-dependent behaviour of composite steelÜconcrete structures." Journal of Constructional Steel Research, 80, 252-263.

Simo, J. and Hughes, T. (1997). Computational Inelasticity. Springer-Verlag.

Spacon, E. and El-Tawil, S. (2004). "Nonlinear analysis of steel-concrete composite structures: State of the art." Journal of Structural Engineering ASCE, 133(2), 159 Ü168.

Spacone, E., Ciampi, V., and Filippou, F. (1996). "Mixed formulation of nonlinear beam finite element." Computers and Structures, 58(1), 71-83.

Tarantino, A. and Dezi, L. (1992). "Creep effects in composite beams with flexible shear connectors." Journal of Structural Engineering, 118(8), 2063-2080.

van Zijl, G., de Borst, R., and Rots, J. (2001). "A numerical model for the time-dependent cracking of cimentitious materials." Internatinal Fournal for Numerical Methods in Engi- 
neering, 52(7), 637-654.

Virtuoso, F. and Vieira, R. (2004). "Time dependent behaviour of continuous composite beams with flexible connection." Journal of Constructional Steel Research, 60(3-5), 451463.

Zhou, F. and Hillerborg, A. (1992). "Time-dependent fracture of concrete: Testing and modelling." Proc., Fracture Mechanics of Concrete Structures, Bažant ZP, ed., Elsevier Applied Science, Amsterdam, The Netherlands.

Zienkiewicz, O. and Taylor, R. (1989). The finite element method. London: McGraw-Hill.

Zona, A., Barbato, C., and Conte, J. (2005). "Finite element response sensitivity analysis of steel-concrete composite beams with deformable shear connection." Journal of Engineering Mechanics ASCE, 131(11), 1126-1139. 


\section{List of Tables}

1 Input values of the constitutive models . . . . . . . . . . . . . . . . . . 29 
TABLE 1. Input values of the constitutive models

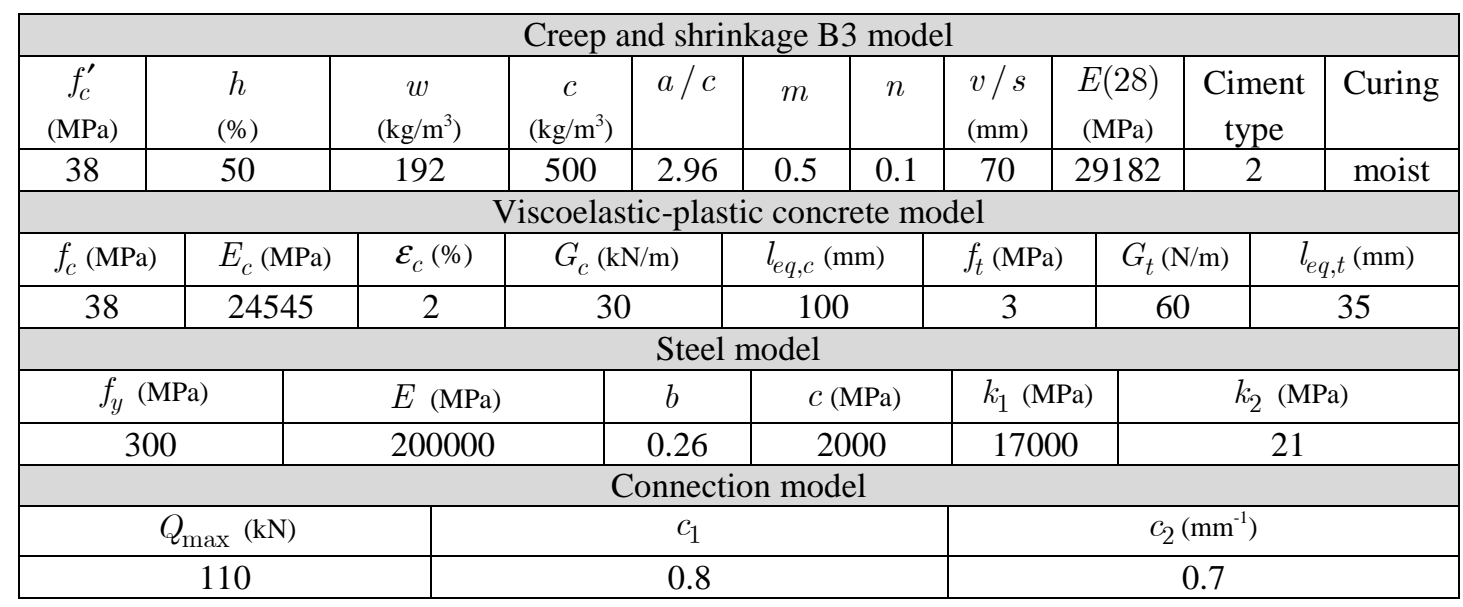




\section{List of Figures}

$1 \quad$ Rheological viscoelastic/plastic model . . . . . . . . . . . . . . . . . . . . . . 31

$2 \quad$ Stress-strain diagram for uniaxial behavior . . . . . . . . . . . . . . . . . . . 32

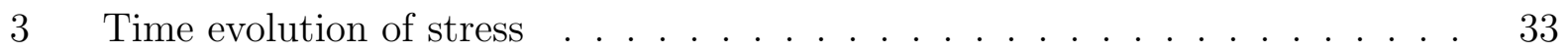

4 Time evolution of strains . . . . . . . . . . . . . . . . . . . . . . . 34

5 (a) Infinitesimal segment of composite beam; (b) Kinematic of composite beam. 35

$6 \quad$ (a) Force degrees of freedom; (b) displacement degrees of freedom. . . . . . . 36

$7 \quad$ Geometry of the composite beams tested by Gilbert and Bradford 1992 . . . 37

8 Numerical-experimental comparison of mid-span deflection versus time curves. 38

$9 \quad$ Evolution of the mid-span deflection: (a) in function of loading for $t=7$ days;

(b) in function of time for $p_{0}=20,30$ and $40 \mathrm{kN} / \mathrm{m}$, respectively. . . . . . . 39

10 Time evolution of hogging bending moment at intermediate support. . . . . 40

11 Time evolution of the most tensile fiber stress at intermediate support. . . . 41

12 Time evolution of the most compressed fiber stress at mid-span. . . . . . . . 42 


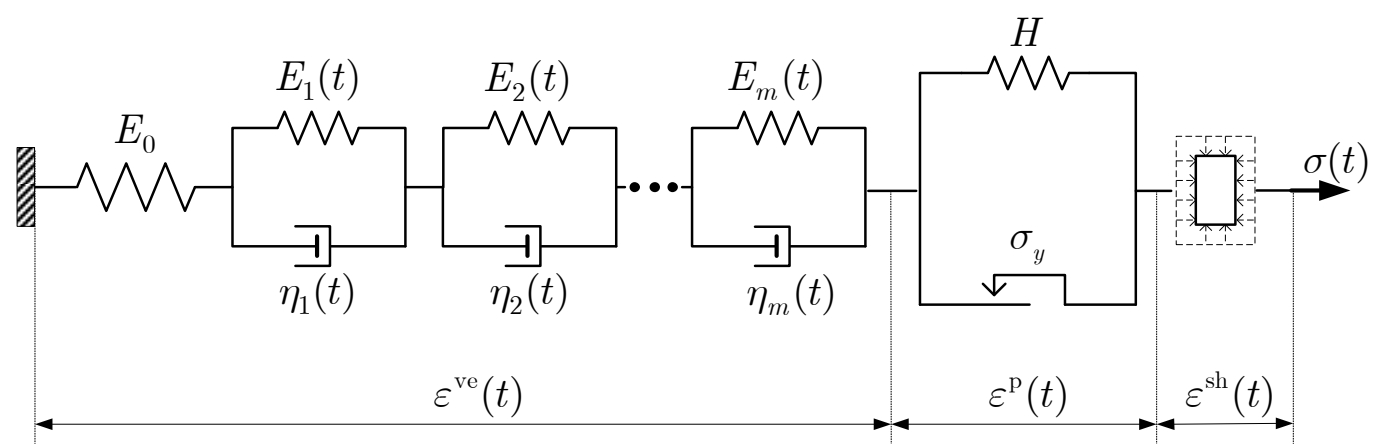

FIG. 1. Rheological viscoelastic/plastic model 

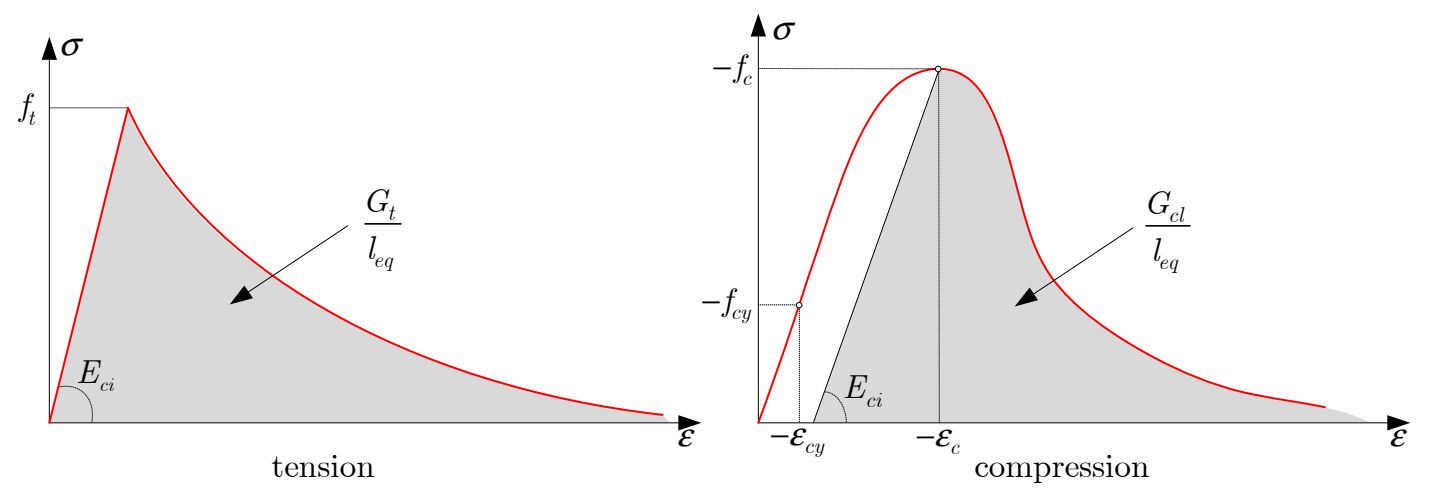

FIG. 2. Stress-strain diagram for uniaxial behavior 


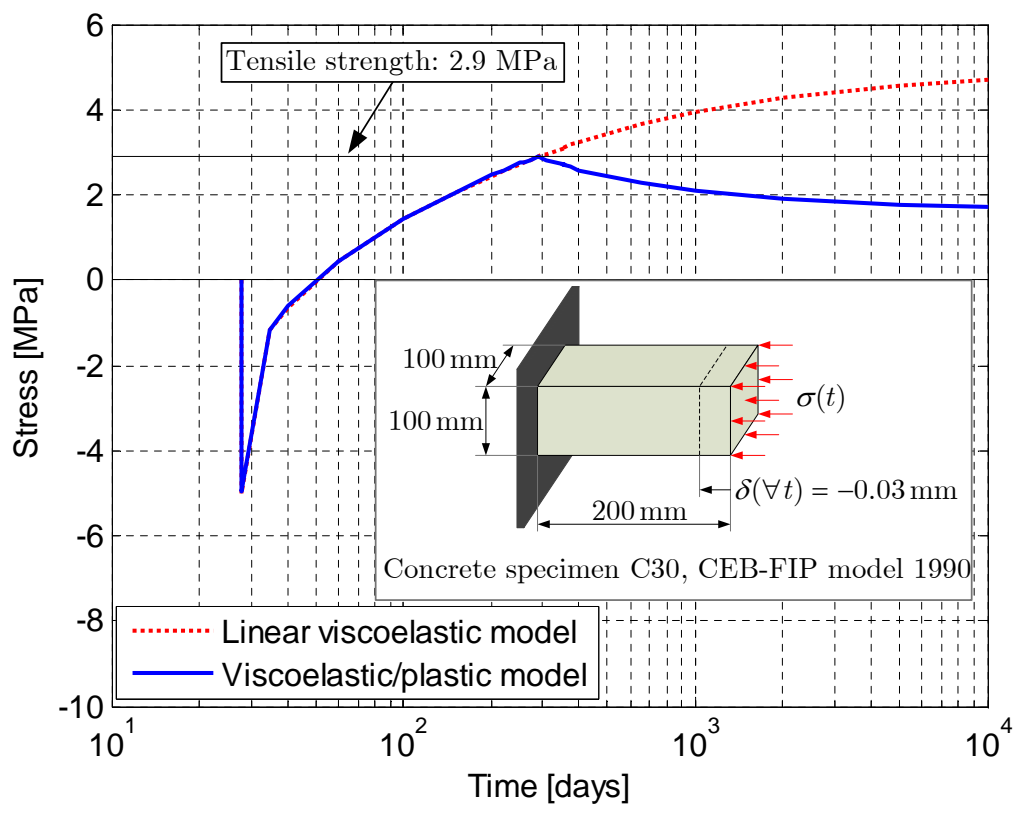

FIG. 3. Time evolution of stress 


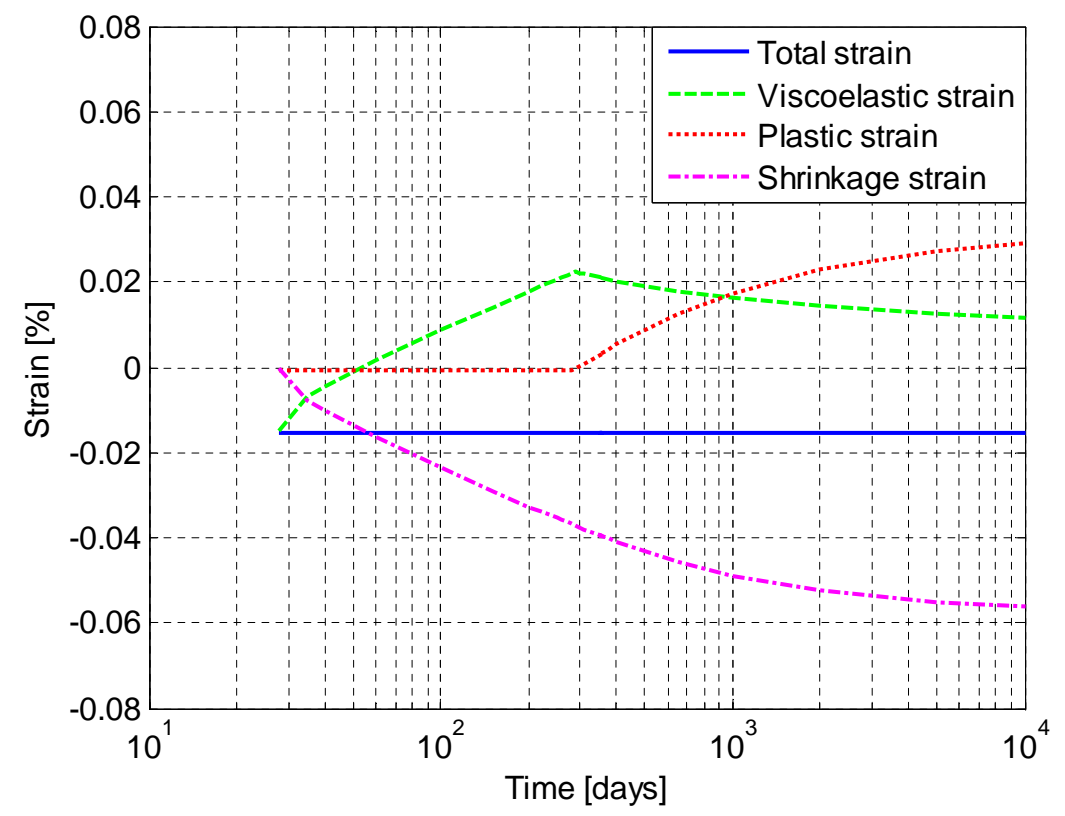

FIG. 4. Time evolution of strains 

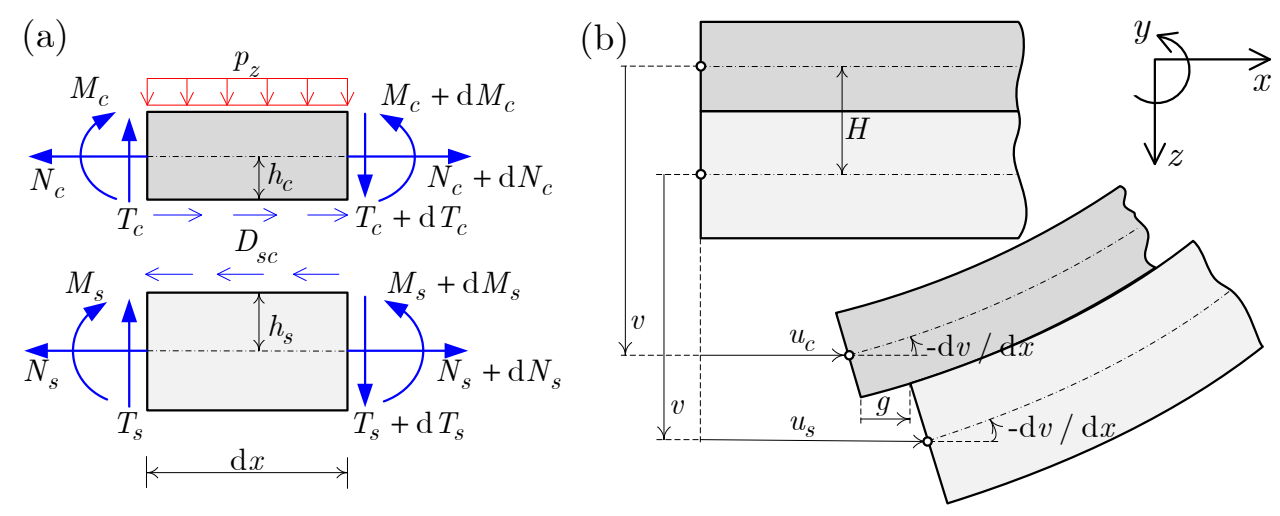

FIG. 5. (a) Infinitesimal segment of composite beam; (b) Kinematic of composite beam. 
(a)

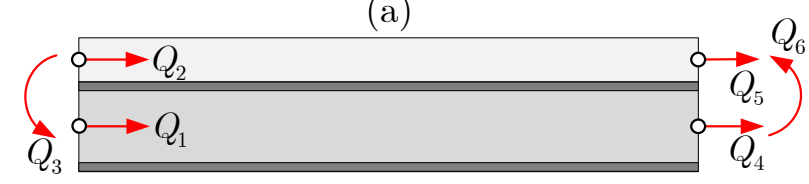

(b)

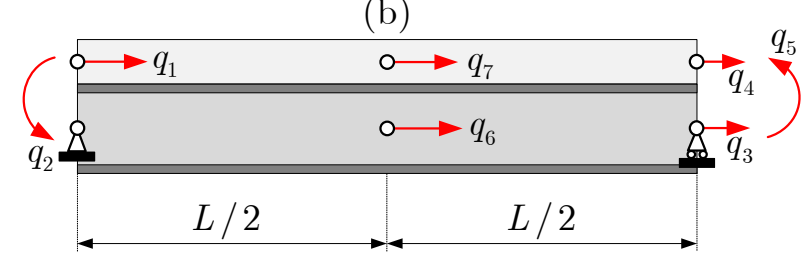

FIG. 6. (a) Force degrees of freedom; (b) displacement degrees of freedom. 


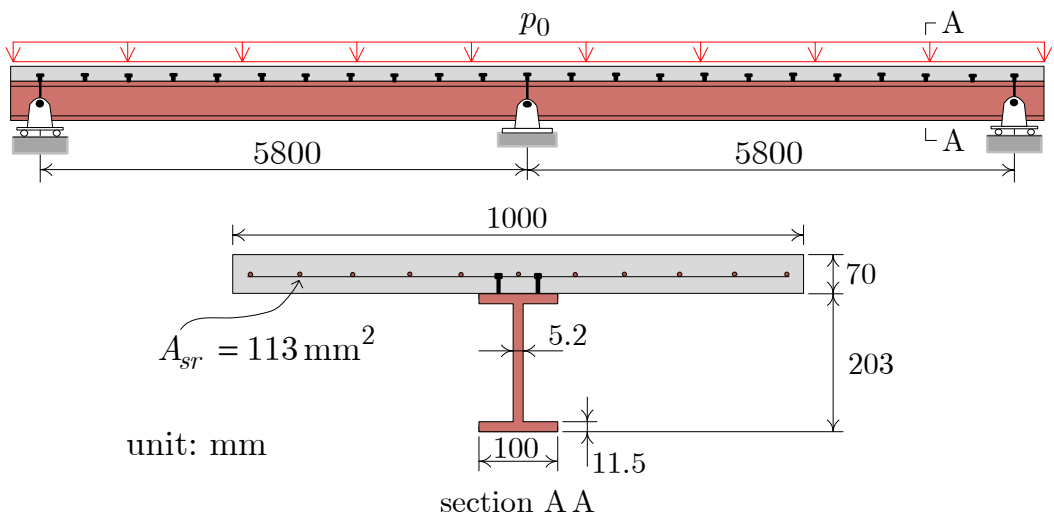

FIG. 7. Geometry of the composite beams tested by Gilbert and Bradford 1992 


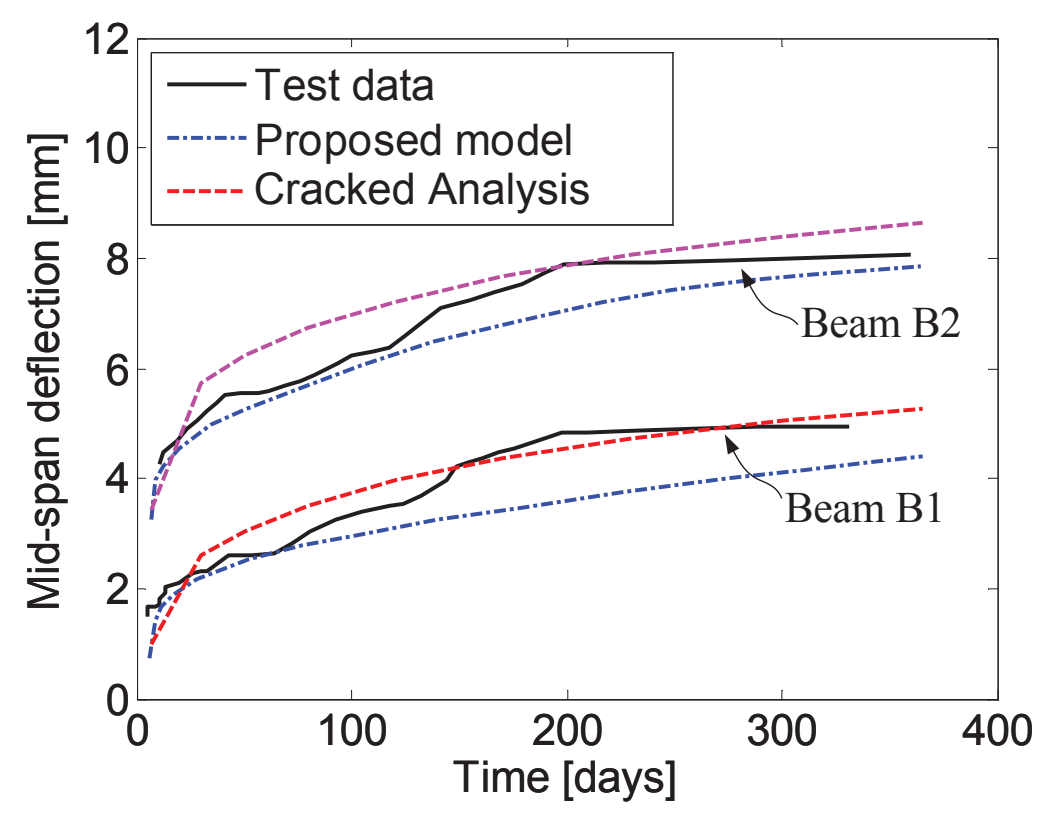

FIG. 8. Numerical-experimental comparison of mid-span deflection versus time curves. 
(a)

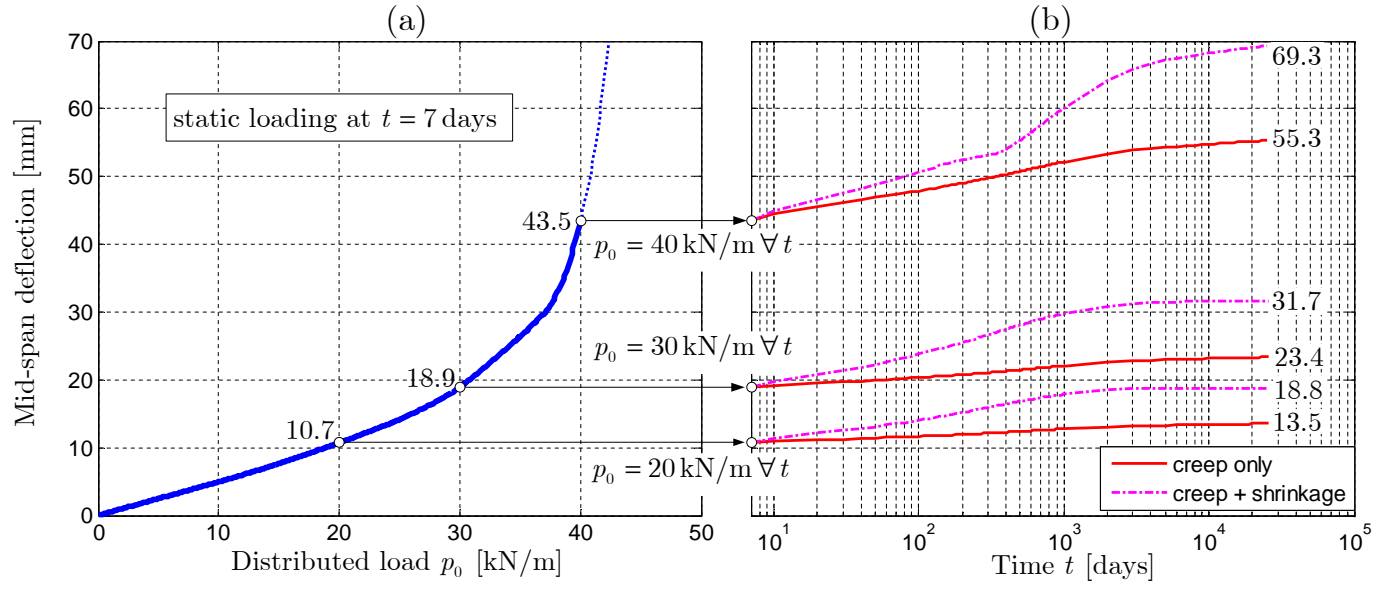

FIG. 9. Evolution of the mid-span deflection: (a) in function of loading for $t=7$ days; (b) in function of time for $p_{0}=20,30$ and $40 \mathrm{kN} / \mathrm{m}$, respectively. 


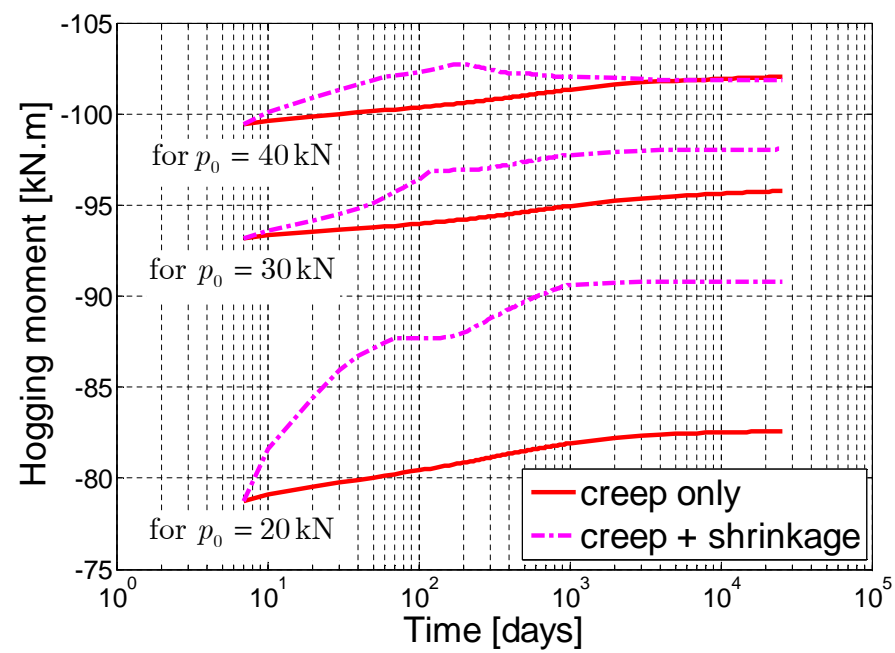

FIG. 10. Time evolution of hogging bending moment at intermediate support. 


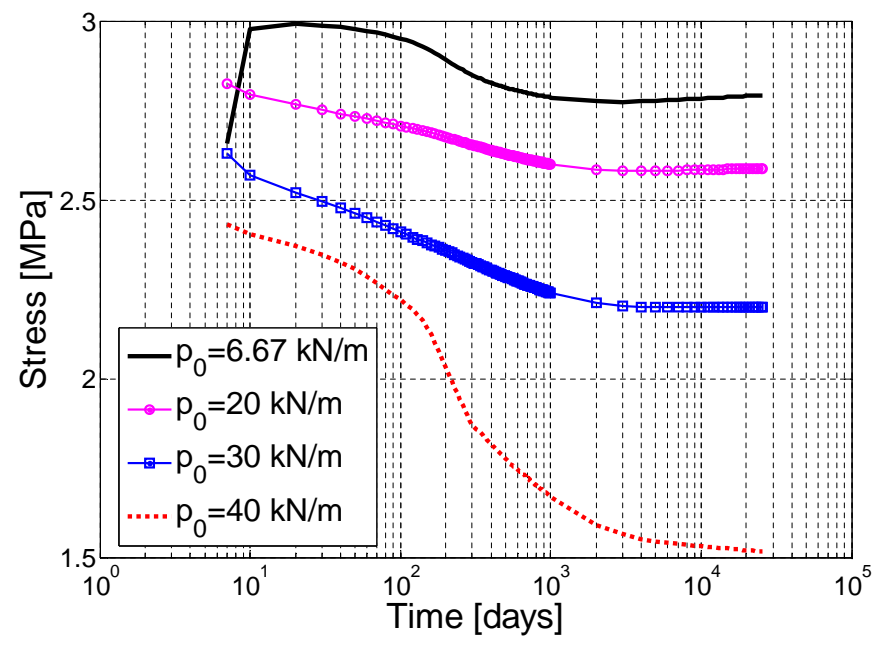

FIG. 11. Time evolution of the most tensile fiber stress at intermediate support. 


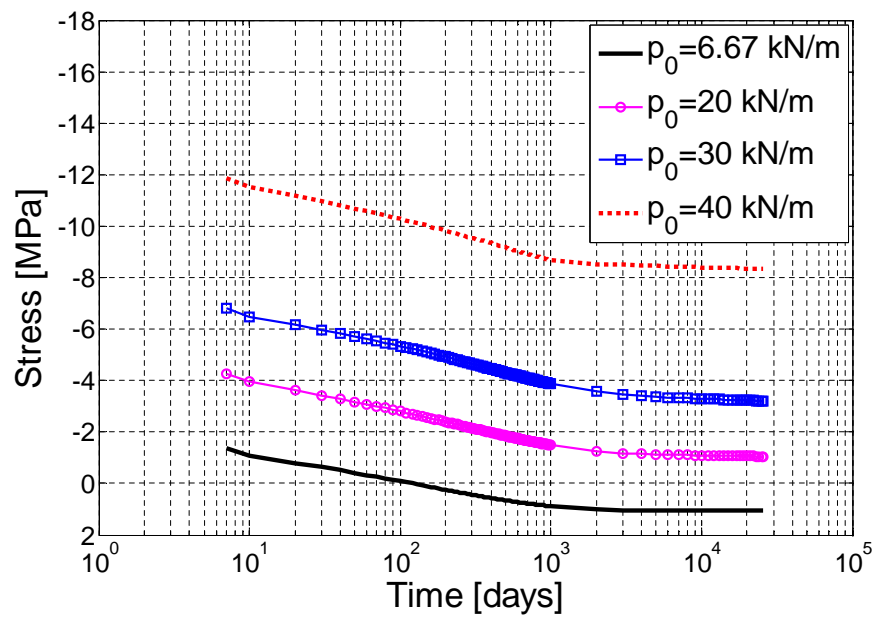

FIG. 12. Time evolution of the most compressed fiber stress at mid-span. 